\section{LETTERS TO THE EDITORS}

The Editors do not hold themselves responsible for opinions expressed by their correspondents. No notice is taken of anonymous communications.

\section{Presentation of Scientific Data}

WoRKERS in certain branches of science have to carry in their heads many numerical results and constants, and to read and abstract a vast literature. This becomes even more arduous for those on the borderline between the exact and the descriptive sciences. The difficulties are greatly increased by the less rigorous presentation of borderline results, and by the less stringent editing of journals dealing with a variety of subjects. In chemistry and in physics the symbols and quantities are standardized, but in the applications littleregard may bepaid to recognized usages. A report drawn up by the Chemical, Faraday and Physical Societies in 1937 listed symbols for thermodynamical and physico-chemical quantities. These were accepted by the Royal Society in 1939. There are, however, many quantities not included in the list. For these, reference to the International Critical Tables or to the Smithsonian Tables is helpful. One major difficulty arises from the fact that the Greek letters and diverse founts of type are lacking on ordinary typewriting machines.

For numerical results it is suggested that, if possible, indices should be avoided, and when used they should refer to the basic unit. Though one may write $17 \mathrm{~cm}$., it is preferable to avoid $17 \times 10^{-4} \mathrm{~cm}$. and to write $17 \times 10^{-6} \mathrm{~m}$., or better, $17 \mu$. This would be an aid to memory.

It would be a convenient convention if droplet sizes were given as diameters, rendering comparable, for example, the length of a bacillus and the diameter of a coccus with spray droplets. But at present those who measure droplets give diameters and those who carry out mathematical investigations give radii.

It is very confusing when quantities in the same enalysis are given in different units. Workers in nutrition are offenders in this. For lack of better, they have to give certain quantities as I.U. (international units), but there is no defence for giving in consecutive lines of a table a vitamin as $19 \mu \mathrm{gm}$. $/ \mathrm{gm}$. and iron as $1.9 \mathrm{mgm} . / 100 \mathrm{gm}$., whereas in fact the two quantities are identical. It would appear simpler to give both results in parts per million. Why do they darken understanding by reporting such quantities as per ounce of, say, bread ? Surely micrograms are meaningless to workers in ounces, but anyone can understand percentages, parts per thousand and per million. Why write $10^{-8} \mathrm{oz}$. ? It sounds ridiculously small and indefinite, but is actually slightly less than $0.3 \mu \mathrm{gm}$. One may be surprised at detecting a substance "even in a concentration of $1 \times 10^{-10} \gamma$ per $\mu^{3 \prime}$, but the feat is more credible when bluntly put as $0.1 \mathrm{gm}$. per litre.

It is somewhat of a shock to find depths of corrosion pits given in thousandths of an inch (mils) and the thickness of the overlying paint in microns, but to give the application of paint in square feet per gallon (Imperial or U.S.A.) is convenient and logical, with just this drawback, that it renders the determination of film thickness-simple in the metric system-quite complicated. Also one wonders why anyone should be allowed to report permeability "as milligrams of water per day per square centimetre of film area per mil of film thickness", or a liquid for destroying insects in cubic centimetres per 37 cubic feet of air, instead of using the factor 2360 to convert to the same unit of volume and reporting as parts in 87,000 or per 100,000 . All the cases instanced have been met with recently. Furthermore, why do physiologists speak of the tension of oxygen, when they mean the pressure-and why, when a paper went to the Chemical Society giving the boiling point of a pure liquid as so many degrees at so many millibars pressure, was it sent back for conversion to millimetres of mercury, though the Meteorological Office publishes the atmospheric pressure in millibars ? Could we not be a little more consistentand spare our memories unnecessary figures? Could we not in technical reports use the metric system universally and translate such quantities as have workshop application into the British system-where necessary? At present there is often a medley of both systems with a vast waste of time in conversion from one unit to another. In measuring light we have even got to the mile-candle. Before autumn one may find candles per acre. After the War, Britain will be poor, so why should we handicap our scientific and technical development by carrying an antiquated system of measurement into new fields? But for those who have to convert, the British Standards Institution Publication 350 (1944) Conversion Factors and Tables is useful.

Department of General Physiology,
Marine Biological Laboratory,

W. R. G. Atkins. Plymouth.

Feb. 12.

\section{Sublimation in a Wilson Chamber}

As a result of some experiments on the deposition of water vapour at low temperatures, it was found that the liquid phase can frequently exist much further below the freezing-point than was expected. For example, droplets of super-cooled water can be obtained at $-50^{\circ} \mathrm{C}$. without difficulty. It appeared also that the number of nuclei in atmospheric air on which water vapour could form ice crystals without the previous formation of droplets was small, and they appear to be active only below about $-40^{\circ} \mathrm{C}$. Arrangements were therefore made to repeat Prof. C. T. R. Wilson's classical experiments below the freezing-point, both in thoroughly clean air and in ordinary atmospheric air. The following results were obtained:

Air thoroughly cleaned by repeated expansions. (1) Provided that the lowest temperature after expansion (that is, the temperature when expansion is finished and condensation just starts) does not fall below $-35 \cdot 0^{\circ} \mathrm{C}$., only liquid droplets are formed, however big is the expansion ratio.

(2) If the lowest temperature after expansion falls to $-35 \cdot 1^{\circ}$ C. $\left( \pm 0 \cdot 1^{\circ}\right)$ a few ice crystals are formed among a much larger number of droplets. As the minimum temperature falls further below - $35^{\circ} \mathrm{C}$., more ice crystals and fewer droplets appear, so that at lower temperatures a fog of ice particles is formed. Whether or not the solid phase appears depends only on the minimum temperature and not at all on the supersaturation.

(3) Provided that the lowest temperature after expansion falls below $-35 \cdot 0^{\circ} \mathrm{C}$, ice crystals are formed although the expansion is below the normal critical ratio. 